\title{
Cascade Configuration of Modal Filters for Power Bus Protection in Differential and Common Modes
}

\author{
Valerii Kosteletskii \\ Tomsk State University of Control Systems and Radioelectronics, \\ 40, prospect Lenina, Tomsk, 634050, \\ Russian Federation
}

Received: February 9, 2021. Revised: July 1, 2021. Accepted: July 17, 2021. Published: July 20, 2021.

\begin{abstract}
The paper discusses the results of quasi-static simulation of two modal filter (MF) cascade configurations designed to attenuate an interference pulse in differential and common modes. The geometric parameters of the MF are optimized by heuristic search according to the amplitude minimization condition. The results of calculating the time responses to an ultrashort pulse (USP) and electrostatic discharge (ESD) are presented. The USP attenuation coefficient in the differential mode was 6.84 times for the horizontally placed cascades, and 6.94 times for the vertical configuration. In the common mode, the attenuation coefficient was 7.35 times for the horizontally placed cascades, and 7.57 times for the vertically placed cascades. For ESD, the attenuation coefficients were 1.51 times for the horizontally and 1.55 times for the vertically placed cascades in the differential and common modes. It was found that only the first spike is attenuated by the ESD excitation on the MF.
\end{abstract}

Keywords - modal filter, electromagnetic compatibility, differential mode, common mode, ultrashort pulse, electrostatic discharge, protection device, multiconductor transmission lines.

\section{INTRODUCTION}

$\mathrm{I}$ $\mathrm{N}$ today's world it is hard to find a field that does not involve electronics. The widespread use of radioelectronic equipment (REE) makes it essential to ensure their safe use as well as their consistent interaction with each other $[1,2]$. Increased mounting density and rising operating frequencies make the equipment more sensitive to electromagnetic interference. In addition, specific operating conditions impose higher requirements on the reliability of the devices used.
For example, in space conditions the REE must be resistant to temperature changes, prolonged overloading, strong vibrations, and humidity. Moreover, as the total radiation dose is accumulated, it must be characterized by stability of parameters and survivability after contact with heavy charged particles [3]. For the uninterrupted operation of the REE it is necessary to ensure a high level of reliability at the design stage. To suppress conducted interference, galvanic isolation devices [4] and electrical filters based on lumped elements are used $[5,6]$. These devices have a list of disadvantages: low reaction time, low power dissipation and parasitic parameters. Due to their disadvantages, these filters are not able to provide the required level of protection against an ultrashort pulse (USP) [7, 8]. Thus, it is relevant to improve the reliability of REE through devices that operate on the principle of modal filtering. Such devices include microstrip modal filters (MF) [9], meander lines [10], reflection symmetric MFs [11], etc. In addition, there are microstrip MFs with a passive conductor in the cutout of the reference plane [12, 13]. In [14], the results of the study demonstrate that an increase in the quantity of passive conductors in the MF allows a larger attenuation of the interfering pulse. The study in [15] shows that a periodic structure of the MF allows increasing the delay difference of modes. Because of their design features, such devices meet the requirements of the hardest operating conditions as they are reliable, simple to build and have low weight. However, they are not capable of suppressing interference in differential and common modes. Traditionally, power circuits in electronic equipment contain two power poles. Two types of interference, the common mode and the differential mode, are propagate in such circuits [16]. The level of such interference is regulated by the standard EN 55022 .

In addition to protection against USPs, it is necessary to provide ESD protection [17]. For example, in [18] it is shown that it is possible to attenuate the first ESD spike. 
In [19] they optimize the MF to attenuate ESD. There is a strip structure that protects against USPs in differential and common mode [20]. This structure was designed to operate in common and differential modes for spacecraft power circuits [21]. Because of the electromagnetic coupling between conductors, such structure is able to operate in common mode and differential mode simultaneously, which cannot be provided by protective devices designed to work in only one mode. The proposed MF has low values of capacitance and inductance [9]. The use of such an MF has no influence on the efficiency of the converter, as can be seen from [22].

In addition there is a way to enhance the effect of modal decomposition with MF cascading. It is necessary that the electrical length of one MF cascade is at least twice the electrical length of the other MF cascade [23]. In addition, to provide the full assessment of this MF type, it is necessary to perform simulations on the impact of several types of a pulse. The purpose of this work is to investigate the effect of MF cascade configurations on the attenuation coefficient in differential and common modes under the influence of a USP and ESD.

\section{SimUlation APPROACHES}

Investigating the effect of the cascade configurations of the multiconductor MF in differential and common mode operation involves the calculation of time response signal waveforms in the TALGAT 2019 software [24] through a quasi-static approach based on the method of moments [25]. The simulation results obtained with the TALGAT software are in well correlation with simulations in other software products and with experimental investigations [26-28].

It was assumed that only the $\mathrm{T}$-wave propagates in the structures of the MF under investigation. In the simulation, first of all, a cross-section of the MF structures was built. After that, the matrices of primary parameters $\mathbf{L}$ and $\mathbf{C}$ were calculated. Then, the matrices of secondary parameters $\mathbf{Z}$ and $\boldsymbol{\tau}$ were calculated. Next, equivalent circuits were drawn, and the resistance values $R_{\mathrm{S}}, R_{\mathrm{L}}, R_{\mathrm{M}}$, and input excitations were assigned. Finally, the responses to the excitation were calculated. Two types of a pulse were used for the simulation. A trapezoidal USP with front, fall, and flat top durations of $100 \mathrm{ps}$ each is shown in (Fig. 1a), and an ESD pulse that has a shape and current amplitude close to the third severity level according to IEC 61000-4-2 - in Fig. 1 b.

To simulate the common mode, the electromotive force (EMF) $E_{\mathrm{S}} 1$ and $E_{\mathrm{S}} 2$ were equal to each other and were fed to the MF input. For the differential mode, excitation pulses

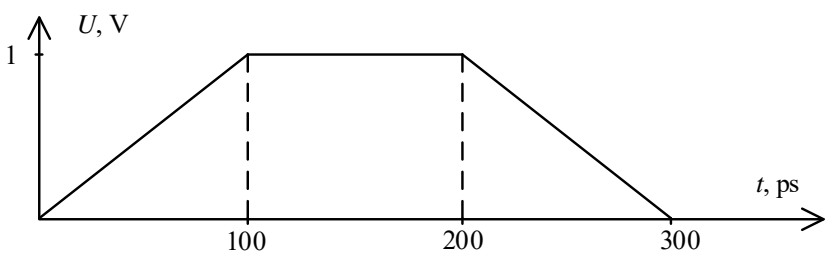

(a)

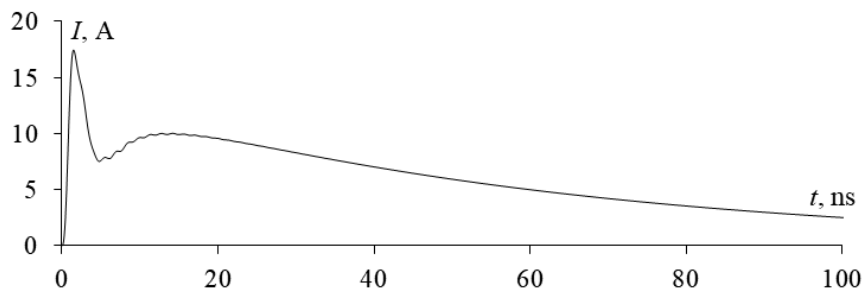

(b)

Fig. 1 EMF waveforms of a trapezoidal USP (a) and an ESD (b). with the amplitude of EMF for $E_{\mathrm{S}} 1$ and $E_{\mathrm{S}} 2$ had different polarity. It should be noted that the EMF of the excitation pulses in the differential mode is equal to half of the EMF in the common mode. The resistance values of the generator $R_{\mathrm{S}}$, load $R_{\mathrm{L}}$ and resistors $R_{\mathrm{M}}$ were also equal to each other and equal $33.69 \mathrm{Ohm}$.

\section{MF CONFIGURATIONS}

To investigate the effect of MF cascade configurations on the attenuation coefficient in differential and common modes, under the excitation of two types of a USP, we will use the equivalent diagrams of the MFs in general form shown in Fig. 2.

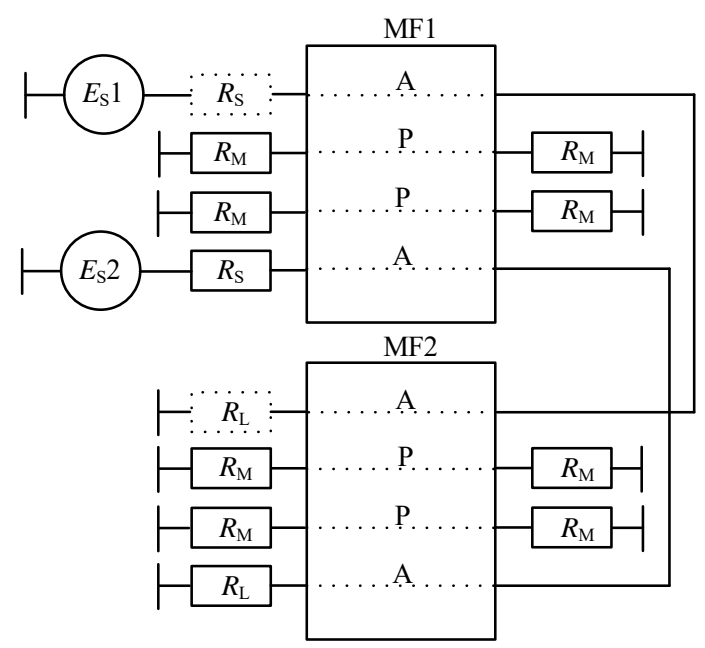

(a)

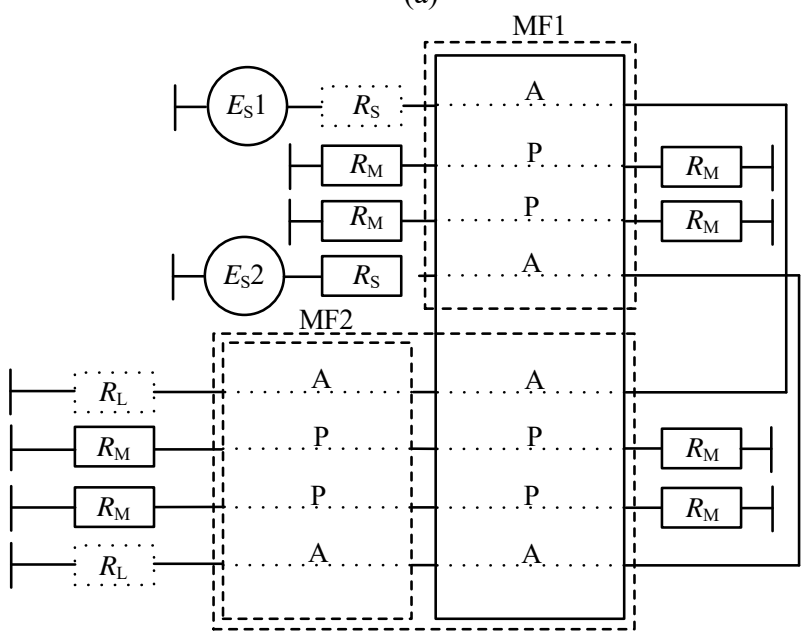

(b)

Fig. 2 Equivalent diagram of the MF under consideration for horizontal $(a)$ and vertical $(b)$ configurations. 
In the diagram, $E_{\mathrm{S}} 1$ and $E_{\mathrm{S}} 2$ are EMF sources, $R_{\mathrm{S}}$ is the value of the generator resistance, $R_{\mathrm{L}}$ is the load resistance, $R_{\mathrm{M}}$ is the value of matching resistors, $\mathrm{A}$ and $\mathrm{A}^{\prime}$ are active conductors, $\mathrm{P}$ and $\mathrm{P}^{\prime}$ are passive conductors, MF1 is the first cascade and MF2 is the second cascade. The length of MF1 is $11 \mathrm{~cm}$ and MF2 is $22 \mathrm{~cm}$.

Two configurations of MF cascades were investigated. In the first, the MF cascades are placed one after another (horizontal configuration); the equivalent diagram of the MF in general form is shown in Fig. 2a, MF1 and MF2 have the cross section shown in Fig. 3a. In the second, the cascades are placed one above another (vertical configuration), and the MF consists of a four-conductor (Fig. 3a) structure connected to an eight-conductor (Fig. 3b) structure, as shown in Fig. $2 b$.

The cross sections of the structures shown in Fig. 3 have the following designations: $w$ is the width of the active and passive conductors, $w 1$ is the width of the reference

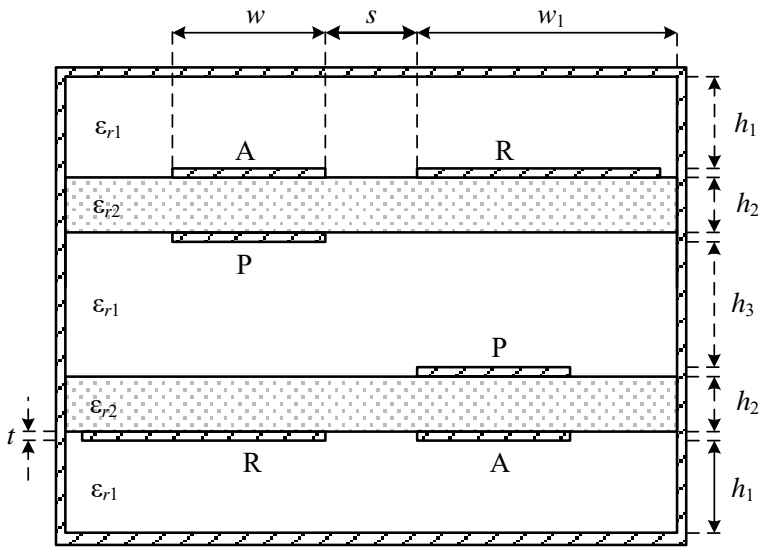

(a)

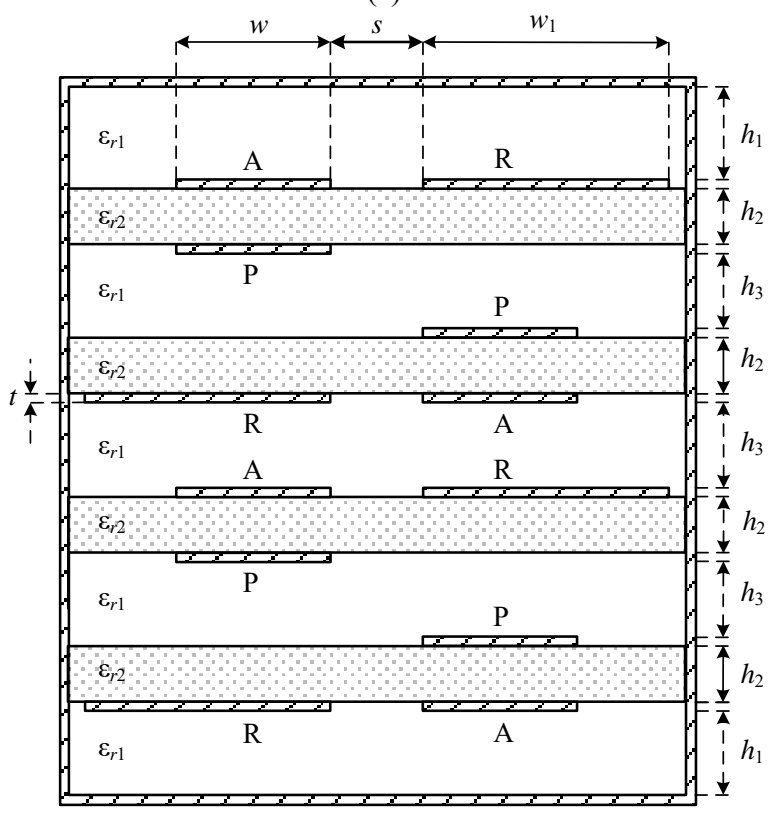

(b)

Fig. 3 Cross-sections of a four-conductor $(a)$ and an eightconductor structures $(b)$, where: $\mathrm{A}$ is the active; $\mathrm{P}$ is the passive; $\mathrm{R}$ is the reference conductors. conductor, $s$ is the distance between the conductors, $t$ is the thickness of the conductors, $h 1$ is the distance from the MF to the shield, $h 2$ is the thickness of the dielectric substrate, $h 3$ is the distance between the MFs, $8 r 1$ is the relative dielectric permittivity of the air, $\varepsilon r 2$ is the relative dielectric permittivity of the substrate.

\section{Simulation Results}

The voltage waveforms at the MF output under the influence of ESD are shown in Fig. 4. The maximum voltage amplitude at the MF input was $565 \mathrm{~V}$ for both modes.

The ESD waveform contains the first spike with a 0.5 level duration of $1.9 \mathrm{~ns}$. Fig. 4 shows that only the first spike is attenuated when the MF is exposed to ESD. Fig. 4a shows that at ESD excitation in the differential mode the maximum voltage at the MF output was $331 \mathrm{~V}$ for the horizontal and $322 \mathrm{~V}$ for the vertical configuration of the MF cascades. We can see that the voltage of the first spike is smaller and equals $311 \mathrm{~V}$ and $285 \mathrm{~V}$, respectively. From Fig. $4 \mathrm{~b}$ it can be seen that the maximum voltage at the MF output was $331 \mathrm{~V}$ for the horizontal and $322 \mathrm{~V}$ for the vertical configuration of the MF cascades in the common mode. The voltage of the

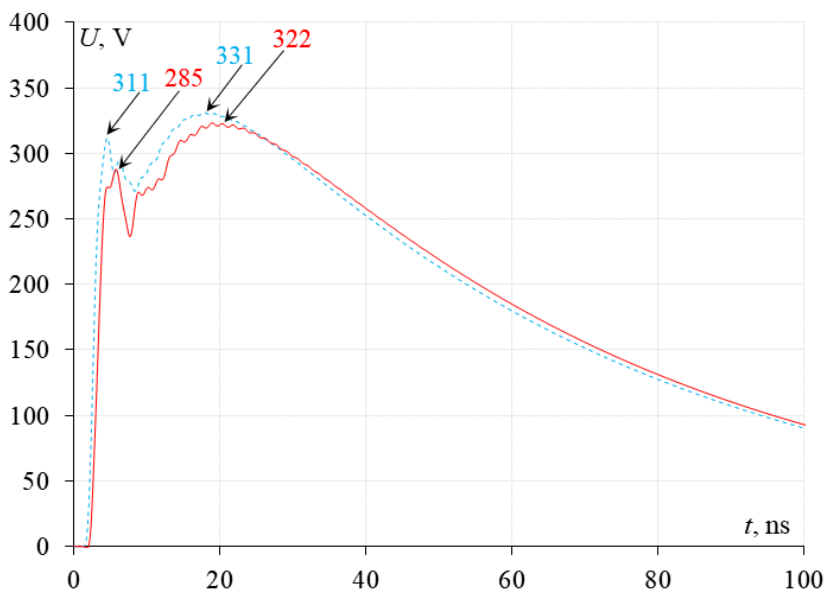

(a)

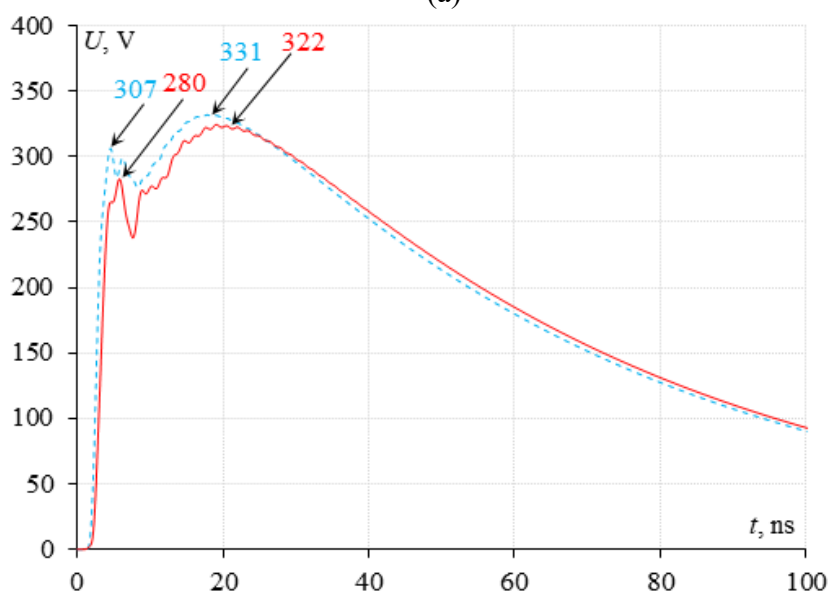

(b)

Fig. 4 Voltage waveforms at the MF output under the ESD excitation in differential $(a)$ and common $(b)$ modes, for horizontal (- - -) and vertical (-) configurations. 
first spike was $307 \mathrm{~V}$ and $280 \mathrm{~V}$, respectively. We can see that the first spike is significantly attenuated, but it does not determine the maximum amplitude at the MF output. Thus, the attenuation coefficients were 1.51 for the horizontal and 1.55 times for the vertical position of the cascades in both modes.

The voltage waveforms at the MF output under the USP excitation are shown in Fig. 5. The amplitude at the MF input was $500 \mathrm{mV}$ for both modes. Fig. 4a shows that the maximum amplitude of the decomposition pulses at the MF output was $73 \mathrm{mV}$ for the horizontal and $72 \mathrm{mV}$ for the vertical configurations of the MF cascades when exposed to the USP in the differential mode. This corresponds to the attenuation coefficients of 6.84 and 6.94 times, respectively. Fig. 4b shows that the maximum amplitude of decomposition pulses at the MF output was $68 \mathrm{mV}$ for the horizontal and $66 \mathrm{mV}$ for the vertical configurations of the MF cascades in the common mode. Thus, the attenuation coefficients were 7.35 and 7.57 times, respectively. In addition Fig. 5 shows that the configuration with vertically placed cascades is characterized by the crosstalk in common and differential modes. In the MF with a horizontal placement of cascades, the maximum amplitude at the MF output is determined

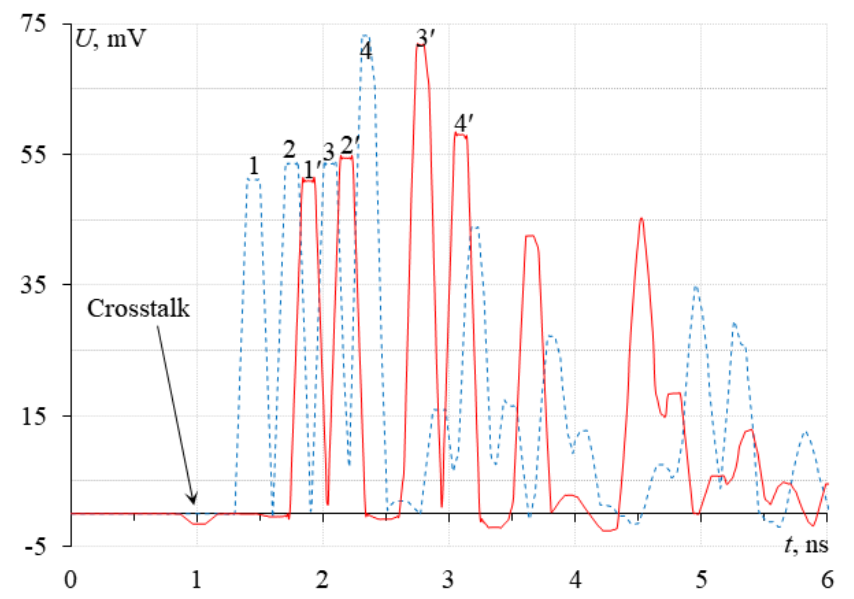

(a)

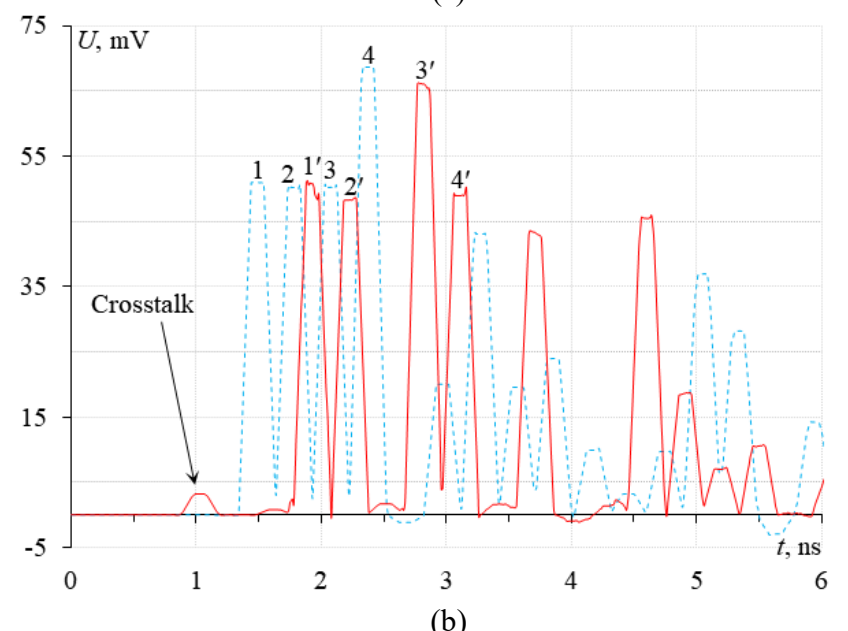

Fig. 5 Voltage waveforms at the MF output under the USP excitation in differential $(a)$ and common $(b)$ modes, for horizontal (- - -) and vertical (- configurations. by the fourth pulse and with a vertical placement of cascades by the third pulse.

Table 1 shows the delays of four pulses that have a maximum amplitude. Thus, in the vertical configuration, the decomposition pulses come later in the differential and the common modes than in the horizontal configuration.

TABLE I. Pulse Delay Time at the Filter OutPut

\begin{tabular}{|l|l|l|l|l|l|}
\hline \multicolumn{2}{|c|}{ Mode } & $\boldsymbol{t}_{\mathbf{1}}, \mathbf{n s}$ & $\boldsymbol{t}_{\mathbf{2}}, \mathbf{n s}$ & $\boldsymbol{t}_{\mathbf{3}}, \mathbf{n s}$ & $\boldsymbol{t}_{\mathbf{4}}, \mathbf{n s}$ \\
\hline \multirow{2}{*}{ DM } & Horizontal & 1.34 & 1.64 & 1.94 & 2.22 \\
\cline { 2 - 6 } & Vertical & 1.73 & 2.03 & 2.61 & 2.93 \\
\hline \multirow{2}{*}{$\mathrm{CM}$} & Horizontal & 1.3 & 1.6 & 1.9 & 2.2 \\
\cline { 2 - 6 } & Vertical & 1.78 & 2.08 & 2.66 & 2.96 \\
\hline
\end{tabular}

With the horizontal configuration the decomposition pulses have approximately equal spacing between each other. With the vertical configuration, the delay between the 2 nd and $3 \mathrm{rd}$ pulses is significantly increased. In the horizontal arrangement of the cascades, the time intervals between all pulses in the common mode are $0.3 \mathrm{~ns}$. In the differential mode, these values between pulses are also 0.3 , except for the value of the interval between pulses with delays $\mathrm{t} 3$ and $\mathrm{t} 4$ where it is $0.28 \mathrm{~ns}$. When the cascades are arranged vertically, the time intervals between pulses with delays $\mathrm{t} 1$ and $\mathrm{t} 2$ in both modes are $0.3 \mathrm{~ns}$; between $\mathrm{t} 2-\mathrm{t} 3$ in both modes they are $0.58 \mathrm{~ns}$; between $\mathrm{t} 3-\mathrm{t} 4$ in the differential mode the interval is $0.32 \mathrm{~ns}$ and the common mode it was $0.3 \mathrm{~ns}$. The change in the time intervals when the cascades are placed vertically is caused by the change in the electromagnetic coupling between the conductors.

To conclude the section, it should be noted that in spite of a low attenuation of ESD, the MF suppresses the influence of the first ESD spike. Thus, the maximum amplitude at the MF output is determined by the second, longest ESD pulse, which has a smaller amplitude than the first spike. When the MF is excited by a USP and ESD in differential and common modes, the maximum value of the interference signal amplitude at the MF output was observed for the horizontal configuration of the cascades. Thus, when the USP was applied to the MF with the horizontal arrangement of the cascades, the maximum amplitude at the MF output was $73 \mathrm{mV}$ in the differential and $68 \mathrm{mV}$ in the common mode. When ESD was applied to the MF with horizontal cascades, the maximum amplitude at the MF output was $331 \mathrm{~V}$ in both modes.

\section{MF WEIGHT CALCULATIONS}

The MF can be installed in any shielding housing at the user's discretion, so the calculation of the MF weight is made without taking into account the weight of the shield. Our calculations of the MF weight were based on the values of the density of the materials used, cross-section parameters and the length of the MF structure. Using the geometric parameters of the MF, we calculated the space of the used material, then got its density from the database, and calculated 
the weight of the MF as shown in:

$$
m_{u}=4 t w l p_{M}+2 t w_{1} l p_{M}+2 h l p_{F R 4}\left(2 w+s+w_{1}\right)
$$

where $p_{\mathrm{c}}$ and $p_{\mathrm{FR} 4}$ are the densities of copper and FR4 glass fiber board, respectively. The density of copper was assumed to be $p_{\mathrm{M}}=8,92 \mathrm{~g} / \mathrm{cm}^{3}$, and for $p_{\mathrm{FR} 4}$, ranging from $1.6 \mathrm{~g} / \mathrm{cm}^{3}$ to $1.9 \mathrm{~g} / \mathrm{cm}^{3}$, the average value was used. Other designations were given in Section III. The weight of the MF without the shielding housing was $7.23 \mathrm{~g}$ for a total length of $33 \mathrm{~cm}$, both for horizontal and vertical cascade configurations. The MF dimensions with the horizontal cascade configuration were the following: the length was $33 \mathrm{~cm}$, the width was $13.7 \mathrm{~mm}$, and the height was $13 \mathrm{~mm}$. With vertical cascade configuration: the length was $22 \mathrm{~cm}$, the width was $13.7 \mathrm{~mm}$, and the height was $19.42 \mathrm{~mm}$

\section{CONCLUSION}

Thus, in this study we investigated the influence of the horizontal and vertical configurations of the MF cascades on the attenuation coefficient. The maximum values of interference signals at the MF output under the excitation of a USP and ESD in the differential and common modes were determined. The USP attenuation coefficient in the differential mode was 6.84 times for the horizontally placed cascades, and 6.94 times for the vertical configuration. In the common mode, the attenuation coefficient was 7.35 times for the horizontally placed cascades, and 7.57 times for the vertically placed cascades. For ESD, the attenuation coefficients were 1.51 times for the horizontally and 1.55 times for the vertically placed cascades in the differential and common modes. It was revealed that only the first spike of the ESD excitation is attenuated on the MF. The weight of the MF without the shielding housing and its dimensions was also calculated. Because of the simple design of the MF, it could be easily implemented as part of the typical technological process used by PCB manufacturers. On the basis of the obtained data the prototypes of the MF will be produced for experimental investigations. The results of experimental studies will be presented in later works.

\section{ACKNOWLEDGMENT}

The research was supported by the Ministry of Science and Higher Education of the Russian Federation (Project FEWM2020-0041) in TUSUR.

The authors sincerely appreciate all valuable comments and suggestions from the reviewers, which helped us to improve the quality of the paper.

\section{REFERENCES}

[1] V.M. Loborev, "The modern research problems. Plenary lecture," Proc. of AMEREM Conference, Albuquerque, 1996, pp. 121-127.

[2] L. Tihanyi EMC in power electronics. Newnes, 1995.

[3] N.G. Chechenin, A.G. Kadmenskij, H.A. Motavekh and
M.I. Panasyuk, "Vozdejstvie vysokoenergetichnyh kosmicheskih protonov i ionov na elementy bortovoj apparatury kosmicheskih apparatov. Poverhnost'. Rentgenovskie, sinhro-tronnye i nejtronnye issledovaniya," pp. 17-17, 2012. (In Russian).

[4] W. Qin, X. Yang, S. Ma, F. Liu, Y. Zhao, T. Zhao, \& B. Chen,"15.5 An $800 \mathrm{~mW}$ Fully Integrated Galvanic Isolated Power Transfer System Meeting CISPR 22 Class-B Emission Levels with 6dB Margin." IEEE International Solid-State Circuits Conference-(ISSCC). IEEE, 2019.

[5] R.L. Ozenbaugh and T.M. Pullen, EMI filter design. CRC press, 2017.

[6] D. Simpson, and D. Psychogiou. "Magnet-less nonreciprocal bandpass filters with tunable center frequency," 49th European Microwave Conference (EuMC). IEEE, 2019.

[7] T. Weber, R Krzikalla, and J. L. Haseborg. "Linear and nonlinear filters suppressing UWB pulses." IEEE Transactions on Electromagnetic Compatibility vol. 46, no. 3, pp. 423-430, 2004:

[8] N. Mora, F. Vega, G. Lugrin, F. Rachidi, M. Rubinstein, "Study and classification of potential IEMI sources," System and assessment notes, Note 41, 8 July 2014.

[9] A.T. Gazizov, A.M. Zabolotsky, T.R. Gazizov, "UWB pulse decomposition in simple printed structures," IEEE Transactions on Electromagnetic Compatibility, vol. 58, no. 4, pp. 1136-1142, 2016.

[10] R.S. Surovtsev, A.V. Nosov, A.M. Zabolotsky, T.R. Gazizov, "Possibility of protection against uwb pulses based on a turn of a meander microstrip line," IEEE Transactions on Electromagnetic Compatibility, vol. 59, no. 6, pp. 1864-1871, 2017.

[11] E.B. Chernikova, A.O. Belousov, T.R. Gazizov, and A.M. Zabolotsky, "Using reflection symmetry to improve the protection of radio-electronic equipment from ultrashort pulses," Symmetry, vol. 11, no. 7, pp. 883, 2019.

[12] M. A. Samoylichenko, Y. S. Zhechev, V. P. Kosteletskii, and T. R. Gazizov, "Electrical characteristics of a modal filter with a passive conductor in the reference plane cutout," IEEE Transactions on Electromagnetic Compatibility, vol. 63, no. 2, pp. 435-442, 2021.

[13] M. A. Samoylichenko and A. M. Zabolotsky, "Simulation the time response to ultra-short pulse excitation of two cascaded modal filters with a passive conductor in the reference plane," Journal of Physics: Conference Series, vol. 1611, p. 1-4, Aug. 2020.

[14] A. O. Belousov, A. M. Zabolotsky, and T. T. Gazizov, "Experimental confirmation of the modal filtration in four- and five-conductor microstrip lines," 2017 18th International Conference of Young Specialists on Micro/Nanotechnologies and Electron Devices (EDM), Jun. 2017.

[15] R. Khazhibekov, A. Zabolotsky, and M. Khramtsov, "Study of the characteristics of a modal filter with 
different periodic profiles of the coupling region," in 2017 International Multi-Conference on Engineering, Computer and Information Sciences (SIBIRCON). IEEE, 2017, pp. 506-509.

[16] P.S. Crovetti, F. Fiori, "Distributed conversion of common-mode into differential-mode interference" IEEE Tran. on Microwave Theory Vol. 59, no. 8, 2011.

[17] X. Huang, J. J. Liou, Z. Liu, F. Liu, J. Liu, and H. Cheng, "A new high holding voltage dual-direction SCR with optimized segmented topology" IEEE Electron Device Lett. vol. 37, no. 10, pp. 1311-1313, 2016.

[18] A.V. Nosov, R.S. Surovtsev, T.R. Gazizov "Investigation of possibility of protection against electrostatic discharge using meander microstrip line" Journal of Physics: Conference Series (JPCS). vol. 1015, no. 2, pp. 1-6, 2018.

[19] Y.S. Zhechev, I.A. Ivantsov, \& A.M. Zabolotsky, "Multicriteria optimization of a four-layer reflectionsymmetric modal filter parameters for ESD protection" Journal of Physics: Conference Series, vol. 1862, no. 1, p. 1-7, 2021.

[20] V. P.Kosteletskii, A. M. Zabolotskiy, Stripe structure protecting against ultrashort pulses in differential and common modes. Patent RF, no. 2748423, 25 May 2021. (In Russian).

[21] Y.S. Zhechev, V.P. Kosteletskii, \& A.M. Zabolotsky "Experimental study of a high current electromagnetic interference filter for the spacecraft power bus" Journal of Physics: Conference Series vol. 1862, no. 1, p.1-6, 2021

[22] S. Khader, A-K Daud, "Optimization of AC Filter for New configuration of single phase current source PV inverter using LabVIEW Platform" WSEAS Transactions on Computers, vol. 18, no 24, pp. 187-197, 2019.

[23] A.M. Zabolotsky, T.R. Gazizov, I.F. Kalimulin, Novye resheniya dlya obespecheniya elektromagnitnoj sovmestimosti bortovoj radioelektronnoj apparatury kosmicheskogo apparata, Publisher of Tomsk state university of control systems and radioelectronics, 2016. (In Russian).

[24] S.P. Kuksenko, "Preliminary results of TUSUR University project for design of spacecraft power distribution network: EMC simulation," IOP Conf. Series: Materials Science and Engineering, vol. 560, no. 012110, pp. 1-7, 2019.

[25] S.P. Kuksenko, T.R. Gazizov, "Usovershenstvovaniye algoritma vychisleniya metodom momentov yemkostnykh matrits struktury provodnikov i dielektrikov v diapazone znacheniy dielektricheskoy pronitsayemosti. Elektromagnit-nyye volny i elektronnyye sistemy”, 2012, 17(10):013-21. (In Russian).

[26] M.A. Samoylichenko, Y.S. Zhechev, V.P.Kosteletskii, \& T.R. Gazizov, "Electrical Characteristics of a Modal Filter With a Passive Conductor in the Reference Plane Cutout" IEEE Transactions on Electromagnetic Compatibility, vol. 63 no. 2, pp. 435-442, 2020.
[27] E.B. Chernikova, A.O. Belousov, T.R. Gazizov, \& A.M. Zabolotsky "Using reflection symmetry to improve the protection of radio-electronic equipment from ultrashort pulses" Symmetry, vol. 11, no. 7, 2019.

[28] P.E. Orlov, T.R. Gazizov, A.M. Zabolotsky "Short pulse propagation along microstrip meander delay lines with design constraints: comparative analysis of the quasistatic and electromagnetic approaches" ACES Journal, vol. 31, no. 3, pp. 238-243, 2016.

\section{Creative Commons Attribution License 4.0 (Attribution 4.0 International, CC BY 4.0)}

This article is published under the terms of the Creative Commons Attribution License 4.0

https://creativecommons.org/licenses/by/4.0/deed.en_US 